\title{
Velos, burkas... moros: estereotipos y exclusión de la comunidad musulmana desde una perspectiva de género ${ }^{1}$
}

\author{
Asun García, Antoni Vives, Carmen Expósito, Socorro PéREZ-Rincón, Lola \\ LÓPEZ; Gemma TORRES; Elisenda LosCOS \\ Grupo “Multiculturalisme i Gènere”, Universitat de Barcelona, \\ asunarmand@gmail.com
}

Recibido: 18.12.2011

Aceptado: 12.01.2012

\section{RESUMEN}

Durante la primera década del siglo XXI ha aumentado la importancia que se ha dado en la esfera pública al fenómeno llamado "inmigración". La diferencia cultural que se ha proyectado sobre los colectivos "inmigrantes" ha sido representada progresivamente en términos de conflicto y amenaza para la cohesión social. Esta representación ha tenido mayor incidencia sobre los colectivos de religión musulmana y en España muy particularmente sobre las personas de origen magrebí, los "moros". Por otro lado los ataques terroristas a Estados Unidos, Gran Bretaña y España, han dado lugar en Europa a manifestaciones de rechazo hacia los musulmanes.

Nuestro primer objetivo es mostrar el papel que juega la imagen estereotipada de la mujer musulmana en la vehiculación del rechazo hacia el Islam, presente en las sociedades occidentales actuales y en Cataluña y subrayar la importancia de los medios de comunicación social en la propagación e incluso la construcción de esta imagen. En segundo lugar pretendemos mostrar como la recepción de los estereotipos por parte de las mujeres musulmanas puede ser subvertido y modificado por ellas, y como estas no pueden ofrecer nuevos caminos para representarlas más allá de la vieja dicotomía oriente occidente

Palabras clave: Género, Islam, mujer, estereotipos.

\section{Veils, burkas... moors: stereotypes and exclusion of the muslim community from a gender perspective}

\begin{abstract}
During the first decade of the 21st century, we have witnessed an escalation in the importance that has been given in the public sphere to the phenomenon called "immigration". Over the past ten years, the cultural diversity that has been projected on the groups identified as "immigrants" has been increasingly represented in terms of conflict and threat to social cohesion. This representation has had the greatest impact on the Muslim community and in Spain most particularly on the people of North African origin, the "Moors". On the other hand the terrorist attacks on the United States, Britain, and Spain, have led to demonstrations of rejection towards Muslims.
\end{abstract}

1 El presente artículo es una síntesis de diversos resultados de los estudios realizados por el grupo de investigación consolidado "Multiculturalisme i Gènere”, en particular de la investigación "Cuestionando la conflictividad cultural: un análisis crítico de las representaciones de la alteridad cultural en los medios de comunicación desde una perspectiva de género" Proyecto I+D+I financiado por el Ministerio de Ciencia y Tecnología (SEJ200763679). 
The aim of this paper is to show the role of the stereotypical image of Muslim women in conveying the rejection of Islam in present contemporary Western societies and in Catalonia, as well as underscoring the importance of media in spreading and even the construction of this image. We try as well to show how the reception of stereotypes by the Muslim women can be subverted and changed, and how they can not offer new ways to represent themselves beyond old dichotomy "east west".

Key words: Gender, Islam, women, stereotypes.

\section{ESPAÑA Y LOS “MOROS”, UNA RELACIÓN CONFLICTIVA}

En España, donde el rechazo a "lo moro" tiene raíces históricas el rechazo a los musulmanes, presentes hoy sobre todo en el ámbito de la inmigración, es según estudios de la UE una realidad creciente y probablemente mayor que en el resto de Europa. ${ }^{2}$

Este rechazo está íntimamente ligado a los estereotipos que acompañan a "lo musulmán” que se difunden en nuestra sociedad y dan lugar a posiciones desvalorizantes y excluyentes que conducen frecuentemente a prohibir su exteriorización. Tengamos en cuenta que en España, a partir del s. XVI "se erigió frente al árabe heroico el moro común, dedicado a profesiones humildes y objeto de sátiras”, una imagen que perdura aun hoy en día (Gonzalez Alcantud, J.A. 2002: 23). La pobreza económica es el principal atributo a partir del que se alterizan a los "inmigrantes" como subdesarrollados y tercermundistas. Sabemos que las identidades se construyen por oposición al otro y nuestro otro era el musulmán-árabe hasta el final de la reconquista y el musulmán-turco en la construcción europea.

Según Robinson, F. (1990: 16), entre los siglos XII y XVIII, la Iglesia hizo hincapié en un ataque al profeta Mohammed. Su vida se convirtió en el centro de atención para tratar de demostrar que era un falso profeta y poner en evidencia la irracionalidad y la agresividad de la religión musulmana. Entre otros cargos, le acusaban de inmoralidad por aconsejar a su pueblo que gozase de su sexualidad (aunque esta recomendación se sitúa dentro del matrimonio). A finales del XIX y principios del $\mathrm{XX}$, dejó de enfatizarse la falsedad de la religión musulmana, los españoles en Marruecos no pretendían evangelizar al pueblo marroquí, sin embargo el Islam se convirtió en elemento fundamental de diferenciación cultural, significaba una diferencia irreconciliable entre marroquíes y españoles (Mateo Dieste, J. L. 1997: 150)

El Islam, considerado desde hace largo tiempo como enemigo del cristianismo, se presenta hoy en "nuestra casa" a través del inmigrante, como un peligro, una amenaza a nuestro reciente laicismo (Aixela, Y. 2001), y es que, como afirmaba Moreras, J. (1999: 11) "las actuales relaciones entre el Islam y Occidente pasan por una evidente fase de desencuentro, en la cual es más fácil insistir sobre la distancia que les

2 Reseñado por Amanda Figueras, 2007 en www.elmundo.es 
separa, que no destacar los vínculos existentes entre ambos”, situación que se perpetua o incluso agrava hoy en día.

Cabe destacar que en España en el momento en que Europa se abandonaba a sus ensueños orientales, más que un orientalismo, se desarrolló un africanismo que no se ensoñaba con un mundo de odaliscas ni eunucos, al contrario, se combatió este tipo de orientalismo que representaba la sensualidad árabe frente a la contención de cristianos y mozárabes. En efecto, España "no buscó el Oriente orientalista, con connotaciones sexuales, sino el África de combates cruentos. En España no se desea al otro, sino que se le combate pues no existen sueños orientales sino de gloria militar" (González Alcantud, J.A. 2002 : 17).

Como nos decían nuestras entrevistadas la discriminación contra los musulmanes es desgraciadamente patente. En efecto según un estudio de la Agencia Europea de Derechos Fundamentales (FRA) el 40\% de los musulmanes que vivian en España (cerca de 1.300.000) fue objeto de discriminación en 2008. La media europea se situaba en el $30 \%{ }^{3}$. Así pues, nos encontramos $-y$ no solamente en Cataluña- ante una islamofobia con diversas manifestaciones.

En el caso concreto de Barcelona, a lo largo de los años noventa del siglo XX, el asentamiento de población pakistaní y magrebí en el barrio de El Raval, antiguo Barrio Chino, uno de los más degradados de la ciudad en aquella época, había convertido este lugar en el paradigma de visibilización en el espacio urbano de la diversidad cultural aportada por la llegada de nuevas poblaciones procedentes del mundo postcolonial. Este proceso de apropiación del espacio público por parte de los recién llegados se significó en parte como la evidencia en la experiencia cotidiana de una nueva invasión silenciosa que amenazaba la homogeneidad cultural y la cohesión social en el marco institucional del estado-nación. Una homogeneidad que debería ser considerada de manera relativa, ya que en este barrio se instalaron desde la década de 1950 numerosos inmigrantes procedentes de diversas regiones del estado español. De todas maneras, la experiencia migratoria en el pasado de muchas personas "autóctonas", o más concretamente "autoctonizadas", residentes en Barcelona -procedentes del sur de la Península Ibérica en su mayoría- rompe la coherencia del discurso de legitimidad de ocupación territorial. En este sentido, la solución discursiva que se da al problema es la tipificación de dos tipos de inmigrantes: los de aquí y lo de allí. De esta manera, a partir del paradigma nacional español se libra a los "inmigrantes interiores" de la alteridad a partir de la que se excluye y discrimina al resto de población de nacionalidad extranjera. Así pues, no son las personas las que por atributos propios se ubican como extrañas, sino una determinada relación la que las coloca en tal posición (Sabido, O. 2009). Es decir, se parte de una posición social desigual y jerárquica desde la que se valora y se coloca a los "otros" al tiempo que reposiciona el "nosotros” (Delgado, M. C. 2009) La distinción que se hace entre los

\footnotetext{
3 Estudio presentado en Madrid el 29/05/2009 y reseñado por Silvia Taules, en www.elmundo.es
} 
antiguos barrios pobres y los actuales "guetos" de concentración de población extranjera procedente del sur y el este, se realiza igualmente cuando se hace referencia al pasado marginal del actual barrio del Raval.

Subrayemos que, siempre sustentado en la antigua representación orientalista del Islam, durante los últimos treinta años se han generado numerosos conflictos a lo largo del territorio catalán que se han manifestado en el rechazo a la apertura de oratorios musulmanes en el espacio público o en la exclusión de las mujeres portadoras de hijab de amplios sectores del mundo laboral. ${ }^{4}$

Parece ser que existe un verdadero problema con el Islam y todos sus componentes: como civilización, cultura, religión..., lo que hace que sea considerado en amplios sectores de nuestra sociedad como definitivamente incompatible con todos los valores de la modernidad occidental.

Cabe preguntarse ¿por qué asusta tanto el Islam? ¿Por qué se valora tan negativamente el hijab, las carnicerías halal, el Ramadán? Cuál es el peligro que representa esta religión? Según Casas, M. (1996) estas cuestiones tienen una sola causa: la ignorancia acerca del Islam.

\section{LA MUJER MUSULMANA, LOS MEDIOS DE COMUNICACIÓN Y LA DEMONIZACIÓN DEL ISLAM}

La oposición entre Oriente y Occidente ha sido históricamente uno de los binomios de representación en los que se ha basado el discurso imperialista de dominio colonial de Europa con respecto a buena parte de Asia y África (Said, E. 1978). El conflicto cultural entre Occidente y el Islam ha tenido unas claras connotaciones de género, ya que la mujer musulmana ha sido emplazada como uno de los principales objetos de diferenciación cultural (Nash, M. 2004).

En la construcción de la diferencia entre ambos mundos el género ha tenido un papel clave, ya que se ha tendido a representar a Oriente como un conjunto de culturas o civilizaciones especialmente crueles y opresoras con respecto a sus mujeres en el ejercicio del predominio social masculino (Spivak, G. 1988). En este sentido, se han fijado en la sociedad europea contemporánea dos elementos como marcadores de las fronteras entre las identidades occidentales y orientales. En primer lugar se ha señalado la utilización del velo ${ }^{5}$ en la presencia pública de las mujeres musulmanas que ha dado lugar a continuas polémicas, ya que se considera esta prenda como la

\footnotetext{
4 En los años 70 del s. XX la presencia musulmana en Barcelona era insignificante, creció a partir de los años 80 y se manifestó claramente a partir de la década de 1990. El primer oratorio se construyó en 1972; la ciudad cuenta hoy con 14 oratorios musulmanes.

5 Palabra con la que, de manera simplista designamos una gran variedad de prendas utilizadas por las mujeres musulmanas para cubrirse la cabeza,
} 
exhibición pública de la identidad religiosa islámica. En segundo término, los matrimonios pactados entre familias que a veces se practican entre el colectivo pakistaní, también han sido interpretados como una muestra de la discriminación de género asociada al Islam y a Oriente en general (Vives, A. y Nash, M. 2009).

En líneas generales, la oposición entre el Occidente moderno y cierto Islam orientalizado y obsoleto se reproduce de manera casi sistemática en la representación de las relaciones de género entre los "inmigrantes" de ciertas procedencias que se realiza a través de la recepción mediática. Esto se manifiesta de forma especialmente diáfana en los debates sobre la viabilidad de parejas mixtas entre población "autóctona” e individuos de religión islámica, considerada especialmente difícil en el caso que sea la mujer la musulmana. En este sentido, la indumentaria con la que las musulmanas cubren su cuerpo vuelve aparecer como el principal obstáculo simbólico para la unión cultural, en este caso más concreto, para la unión conyugal: 6

Los medios de comunicación juegan un papel protagonista en la vehiculización de las imágenes sobre los colectivos inmigrados y en particular sobre sus mujeres. Si bien estas "inmigrantes" se encuentran infra-representadas en los medios, en los pocos casos en los que aparecen, lo hacen como portadoras de los estereotipos más recurrentes sobre sus culturas de origen, lo que las convierte en símbolos de su comunidad de origen (Nash, M. 2003). Así se define una comunidad imaginada de mujeres "inmigrantes", que las aglutina en un grupo homogéneo y sirve para alimentar creencias colectivas a través de las que se articulan las pautas de inclusión y exclusión social.

En esta línea, la exhibición pública de la procedencia diferenciada, muchas veces llevada a cabo por mujeres "inmigrantes" a través de ciertas indumentarias, en particular las diversas ropas combinadas con una pieza para cubrir la cabeza, se ha interpretado como una amenaza para la pureza cultural y la cohesión social de los estados nación occidentales (Martín Muñoz, G. 2000). ${ }^{7}$ El vestido que utilizan estas mujeres, "no sólo sorprende, sino molesta, cuando no ofende" (Aixela, Y. 2001).

Ello ha afectado en gran medida la vida cotidiana de las mujeres de origen marroquí en Barcelona y Cataluña, ya que ha generado conflictos de convivencia como por ejemplo el que gira en torno al debate sobre la aconfesionalidad de la educación pública y el derecho individual de las chicas musulmanas a llevar el velo en los cen-

\footnotetext{
6 Focus group celebrado el 26 de abril de 2009 en el IES Maria Aurèlia Campmany de Cornellà de Llobregat con 7 profesores “autóctonos”: 2 hombres y 5 mujeres.

7 Cabe destacar una cierta dicotomía en la apreciación de las prendas utilizadas por las mujeres musulmanas. Es en realidad la combinación de las ropas portadas, aun cuando sean próximas a las de uso en Occidente, con un cubrecabeza (hijab, dupata_u otro) lo que molesta, o incluso atemoriza, mientras que las ropas de aquellas musulmanas que dejan libre la cabeza, aun siendo tradicionales, se consideran desde un imaginario exotizante de manera positiva, como es el caso del bubu y pagne de las africanas o el kemiz shalvar de las pakistaníes y muy en particular el sari de las indias.
} 
tros escolares. Las medidas de disciplina social contra este tipo de prendas han llegado a su episodio cumbre con la prohibición del burka en los edificios públicos que varios ayuntamientos han promulgado en 2010, a pesar de que esta indumentaria es prácticamente inexistente entre la comunidad musulmana catalana.

El rechazo a "lo musulmán” se vehicula pues en gran medida a través de la mujer, considerada como víctima, no de un patriarcado, sino de su religión, y representada como el arquetipo de la mujer oprimida, lo cual la condena a una representación estereotipada. Cuando en Occidente se habla de la supuesta discriminación de las mujeres musulmanas, se obvian los verdaderos orígenes de esta situación, "se da por sentado que su religión es el origen de sus males, en vez de buscar las causas en la política de los Estados correspondientes y la herencia sociocultural patriarcal de sus sociedades” (Moualhi, D. 2000: 292)

Son numerosas las pensadoras e investigadoras musulmanas o especialistas en el mundo musulmán que hacen hincapié en que no es la religión sino el patriarcado lo que incide negativamente en la situación de sus mujeres. ${ }^{8}$

"De hecho, el verdadero problema que se plantea, no es tanto el Corán, sino lo que se ha hecho de este Corán durante siglos y siglos de lectura y de interpretaciones sexistas hacia la mujer" (Lamrabert, A. 2004).

Pensar que los problemas a los que se enfrentan las mujeres en las sociedades musulmanas son fenómenos derivados únicamente del Islam y de su identidad religiosa impide, según Forti, R. (2002) tener una comprensión de las desigualdades estructurales y de los esfuerzos de aquellos que luchan por un cambio en sus sociedades, que en ocasiones pagan con sus vidas, y más habitualmente con su libertad.

Hay que subrayar que los componentes esenciales del patriarcado en una sociedad musulmana no son diferentes de los que encontramos en otras partes. Sin embargo, como avanza esta autora, aunque las estructuras patriarcales y las prácticas discriminatorias que de ellas derivan son similares dentro y fuera del mundo musulmán, no hay que olvidar que:

"La religión, uno de los rasgos característicos de la definición que las personas dan de sí mismas y de sus culturas, influye en el perfil de las vidas de las mujeres y en sus posibilidades de autoafirmación. En gran parte del mundo musulmán, el Islam es una realidad cotidiana para la gente. Es parte integral de cómo se definen a sí mismos en la sociedad" (Forti. R. 2005).

8 En este contexto citaremos a Djaouida, Moualhi, Romina Forti, Asma Lamrabet, Fatima Mernissi, Nawal al- Sa'dawi, esta es igualmente la posición de algunas organizaciones feministas musulmanas como Sisters in Islam. 
En este sentido el patriarcado no sería el aliado sino un gran enemigo del Islam, ya que "el mundo islámico traiciona cada día que pasa el espíritu de su religión, al tener un comportamiento distante años luz de la dimensión espiritual del mensaje" (Ibíd.).

Este rechazo se ejemplifica, como ya hemos mencionado, a través del hijab, considerado unilateralmente como emblema del Islam y signo de retraso y opresión y negándole la variedad de connotaciones que hoy conlleva, excluyendo a su portadora en amplios ámbitos de nuestra sociedad. En efecto, como algunas de las informantes de nuestro estudio, manifestaron, el hijab ciega la vista a cualquier otra cualidad o aptitud de su portadora, como por ejemplo un alto nivel en formación, incluso universitaria. El hijab, se toleraría, según ellas, no se respetaría, y esto sólo en el ámbito de la mediación.

Las continuas polémicas sobre el hijab y su presencia en el espacio público constituyen un conflicto generado por estas formas de representación estereotipada de la alteridad. De hecho, la necesaria significación del velo islámico como síntoma de desigualdad patriarcal asociada a la cultura de origen, ha sido repetidamente negada por la propia experiencia de las mujeres musulmanas que deciden llevarlo (Aixelá, Y. 2000; Mohuali, D. 2000, Badran, M. 2009) El velo es en definitiva el "paradigma de la no-comprensión de la otredad”(Bracco, C. 2007).

Por oposición a Occidente las mujeres del llamado "tercer mundo", en particular las musulmanas, también han sido asociadas a la ignorancia, al fervor religioso irracional y al atraso social. En su mayor parte, han sido claramente caracterizadas como víctimas irrevocablemente sometidas a las disciplinas patriarcales propias de su cultura (Mohanty, Ch; Russo, A. 1991). De esta forma, las procedencias alterizadas han sido presentadas como sociedades a las que se corresponden unas relaciones de poder inmutablemente discriminatorias con respecto al género femenino (Ahmed, L. 1992). Y es que el "machismo es latino en el sur de América, mediterráneo en el sur de Europa, pero peligrosamente islámico en el Magreb” (Lamrabet, A. 2002) .

La mujer musulmana se representa pues como víctima de una tragedia que la perseguirá desde su nacimiento. ${ }^{9}$ La sumisión femenina y reclusión domestica atribuidas a las mujeres orientales musulmanas conforma el conjunto semiótico que se asocia a la religión islámica y al velo como signo de exteriorización de la diferencia cultural. Esta visión religioso-culturalista tendría según Benhabib, S. (2002) un efecto perverso, ya que cuestionar los comportamientos de estas mujeres desde la perspectiva cultural las dejaría prisioneras del patriarcado del que intenten escapar.

\footnotetext{
9 Desde esta lógica, la colonización europea ha sido planteada como la salvación de las mujeres nativas, sobre todo en el caso de las musulmanas.
} 
A. García et. al Velos, burkas... moros: estereotipos y exclusión de la comunidad musulmana...

Existe en Occidente un cierto voyeurismo ante estas "tragedias, que tiene como efecto desviar la atención de nuestras propias realidades, "nada hay que más guste en Occidente que esas tragedias que le hacen olvidar sus propios crímenes” (Moualhi, D. 2002).

Estas “tragedias” dan, por otro lado, razones para el rechazo del Islam. Es así que los estereotipos sobre la situación de las mujeres musulmanas son posiblemente el instrumento más eficaz para demonizar sus sociedades y muy particularmente su religión.

Pero a quienes elaboran este discurso victimizante y excluyente no les interesa para nada la situación de la mujer musulmana, sino el cumplimiento de sus estereotipos. "La mujer musulmana como tal no es vista por los occidentalistas, no les interesa, no les preocupa cuáles pueden sus problemas o inquietudes” (Forti, R. 2005).

Un importante pilar en el que se sustenta esta aversión ante los musulmanes es que no se les considera como productores de cultura, lo que es en definitiva toda sociedad humana, sino productos de su cultura, juzgada como anclada en el tiempo e inamovible, en la que las mujeres serían vehículo de estos valores obsoletos. También el binomio cultura/religión, frecuente en el pensamiento occidental, se aplica implacablemente a la comunidad musulmana y principalmente a la marroquí. En efecto, el halo de orientalismo que proyectamos sobre colectivos musulmanes procedentes del Sur de Asia, o el exotismo atribuido a los africanos, les pone al abrigo en cierta medida de estos juicios.

Cabe destacar que a la gradación de diferenciación cultural establecida en base al binomio de significación inmigrante-autóctono, se establecen ciertas distinciones entre la "inmigración” peligrosa no deseada y la preferente cuyas procedencias no representan una amenaza para la cohesión social en un grado tan alto (López García, B. 2000). Tanto políticos como intelectuales han propuesto desde los inicios del fenómeno la preferencia de unas procedencias de migración a otras a partir de argumentos de similitudes culturales y religiosas con respecto a la sociedad de recepción. De esta manera, han sido considerados preferibles latinoamericanos a magrebíes y cristianos a musulmanes.

A partir de estos mismos esquemas nacionalistas de alteridad y exclusión de la población extranjera, de la comunidad local imaginada, la concentración de la residencia de los recién llegados en determinadas áreas urbanas se interpreta como una usurpación ilegítima del espacio propio. Los signos urbanos visibles de esta "usurpación”, como es el caso de los lugares de culto, y como ya hemos mencionado, el hijab de las mujeres, casi exclusivamente musulmanes ${ }^{10}$, son considerados como un ataque a la homogeneidad de la sociedad autóctona.

10 El halo de exotismo con el que envolvemos las religiones del extremo Oriente resulta en una mayor aceptación de sus lugares de culto, que incluso a veces buscamos con avidez. 
En el curso de nuestras entrevistas en muchas ocasiones esta forma de representación de la alteridad oriental aparece de forma súbita incluso cuando no es el tema de debate planteado en el discurso mediático. Así por ejemplo durante nuestro estudio, en la proyección de un corte del programa Tot un Món, se mostraba la iniciativa empresarial de las mujeres marroquíes a través del trabajo cotidiano en una peluquería. ${ }^{11}$ Ante el visionado del video, la recepción “autóctona” desplazó el tema de debate al tópico recurrente sobre la mujer musulmana en Europa y la presencia del velo en el espacio público. ${ }^{12}$ De esta manera se abandonaban los planteamientos de la proposición de emisión centrados en cuestiones puramente económicas y de estética femenina.

La razón de este desplazamiento radica sencillamente en el hecho que la propietaria del establecimiento era marroquí y trabajaba con el hijab puesto. De hecho, la joven combinaba el pañuelo con una indumentaria perfectamente adaptada a los usos locales. En este punto se delimitan de forma nítida las fronteras entre el "nosotros" occidental como sujeto dominante y la "otra" oriental que debe aceptar y someterse a las disciplinas de integración que implican el abandono del uso de esta prenda:13 Como una de las entrevistadas dijo:

"Pero ellos no se acercan tanto porque la peluquera que está peinando con su pañuelo, esta transmitiendo su cultura. No se esta integrando tanto hacia nosotros”

Transmitir su cultura no es pues un enriquecimiento sino un obstáculo a la integración. La jerarquización cultural de las diferentes prendas de vestir se manifiesta en la selección léxica de ciertos términos despectivos o cierto vocabulario asimilado a los lenguajes de colonización: ${ }^{14}$

"Ellos se tienen que integrar, quitarse un poco esos prejuicios, esas ropas, aunque yo tampoco quiero meterme en esas cosas.... Hay que intégrala hacia ti y que no vaya con este rollo del pañuelo”.

En este sentido, la selección de la expresión "ese rollo" para denominar el pañuelo implica una actitud desvalorizante y jerarquizante. Las jerarquías culturales precisamente son remarcadas al asociar la prenda al término "prejuicio" tradicionalmente opuesta al concepto de razón en el viejo discurso ilustrado de civilización eurocéntrica con el que se han legitimado históricamente los procesos de colonización.

Por otro lado, y como hemos podido constatar durante nuestro estudio, la representación de la subjetividad de las mujeres musulmanas y de su agencia social es

11 “Perruqueria Noor”, emitido por TV3 en el programa Tot un Món el 18 de Noviembre de 2006

12 Focus groups celebrados el 23 de enero y 12 de febrero de 2009 en la Facultad de Geografía e Historia de la UB con 6 mujeres “autóctonas” de entre 30 y 45 años.

13 Ibíd.

14 Ibíd. 
recibida con sorpresa por las audiencias exógenas a dichos colectivos. En este sentido, ante la noticia de la celebración en 2005 de un congreso islámico y feminista en Barcelona, ${ }^{15}$ estudiantes latinoamericanas reaccionan en silencio con estupefacción y sorpresa. Solamente al cabo de un rato significan esta información como la excepción que confirma la norma de sumisión femenina y reclusión doméstica de la mujer orientalizada en el Islam:16

"Está bien será que algunos padres dejan que sus hijas tengan su propio... o elegir a sus propios maridos [...] porque hay excepciones claro. Hay una mayoría y hay una minoría”.

Además de las imágenes negativas existen también otras que constituyen una cierta mitificación, un imaginario «romántico» que atribuye a las sociedades musulmanas un atractivo exótico (Robinson, F.1990 y Said, E. 1995). La postura idealista permite a algunos occidentales alcanzar sus ilusiones, ya sea en sus fantasías o en aventuras escogidas a la carta. Por otro lado este exotismo hace que en determinados ámbitos, particularmente el festivo, lo musulmán, desde su perspectiva exótica, sea no solamente aceptado sino deseado y haga por un tiempo determinado desaparecer la barrera que nos separa de lo "amenazante" que le atribuimos. Pero este exotismo, lejos de acercarnos a la realidad oriental, la envuelve en un inmovilismo del que no la dejamos escapar.

\section{LA VISIÓN “AL OTRO LADO DE LA BARRERA”}

¿Pero como perciben la mujeres musulmanas los estereotipos que se les aplican? Como pudimos constatar durante nuestras entrevistas, la recepción del discurso mediático sobre las relaciones de género entre "inmigrantes" basada en el binomio de diferenciación entre Oriente y Occidente cambia radicalmente cuando la audiencia está conformada por mujeres árabes-musulmanas. En algunos casos incluso, en el seno de los colectivos clasificados como "inmigrantes", se considera que el conflicto cultural no proviene directamente del discurso hegemónico sino que se atribuye a la intolerancia predominante ante la diferencia cultural y las minorías. Este es el caso de un grupo de mujeres marroquíes que niegan el estereotipo de la alteridad con el que se las ha identificado, al mismo tiempo que intentan evidenciarlo como una construcción social y un prejuicio irracional de los medios de comunicación, las instituciones públicas y la población “autóctona” en general

“Hay mucha gente que no le gusta la gente de Marruecos. No sé porqué. La gente ve las noticias y piensa que todos los musulmanes somos terroristas. Tienen miedo de Marruecos. / La gente no quiere alquilar pisos a los inmigrantes. No quieren

15 El País, 04/11/2006

16 Focus group celebrado el 30 de abril de 2009 en el IES Maria Aurèlia Campmany de Cornellà de Llobregat con 7 alumnas “inmigrantes” de procedencia latinoamericana y marroquí. 
extranjeros, de Marruecos. / El problema para las mujeres es el pañuelo. Cuando buscas trabajo siempre te preguntan si llevas pañuelo”. ${ }^{17}$

Así pues, las mujeres inmigrantes procedentes no solo del Magreb sino también de otros países musulmanes dan significado a su propia experiencia de discriminación laboral y residencial como actos de xenofobia cultural. Más específicamente, identifican las disciplinas sociales que padecen como ataques a su propia cultura de procedencia incluyendo la religión. En este aspecto, la significación occidental y alterizante del velo islámico como signo de intolerancia religiosa y autoritarismo patriarcal adquiere una posición central en la disputa cultural (Martín Muñoz, G. 2000). La experiencia de las disciplinas de integración que se imponen a las mujeres marroquíes con motivo de esta prenda de vestir es interiorizada por ellas mismas como una forma de discriminación cultural y un atentado a su libertad individual:

"Mi jefa cuando viene a buscarme a casa, me obliga a entrar en el coche sin pañuelo. Yo ya entro al trabajo sin pañuelo, pero ¿por qué en el coche? Es cosa mía. / El problema para las mujeres es el pañuelo. Siempre te miran y te dicen ¡qué calor!”18

Así pues, un grupo de mujeres marroquíes dedicadas a la mediación cultural reaccionaba de manera ostensiblemente diferente ante programas televisivos como Tot un Mon en los que se enseñaba mujeres trabajando con el pañuelo puesto. ${ }^{19}$ Las mujeres musulmanas afirman ante todo la evidencia de las imágenes que recaen sobre sí mismas como estereotipos que poco tienen que ver con sus experiencias personales. En este sentido, demuestran un buen conocimiento de las representaciones de la alteridad oriental que se transmiten en los medios de comunicación: 20

“Este es el problema de la sociedad, como presentan el estereotipo: todas somos incultas, llevamos pañuelo y no sabemos hacer nada”

En todo momento, estas mujeres diferencian lo que en su opinión son realmente ellas mismas, de cómo son vistas por el resto de la población, cosa que las estimula a mostrar la evidencia de los estreotipos y a denunciarlos.

Ello les conduce al cuestionamiento de las políticas mediáticas de representación de sus personas. En este sentido, denuncian la imagen sesgada, que según ellas, se ofrece repetidamente en los medios de comunicación sobre su país de procedencia:21

17 Focus group realizado en la Escola d’adults “Martinet de Nit”, Districte de Sant Martí, Barcelona el 2 de marzo de 2009. Participaron 11 mujeres "inmigrantes” de entre 25 y 52 años: 10 de nacionalidad marroquí y una de nacionalidad búlgara.

18 Ibíd.

19 “Perruqueria Noor”, emitido por TV3 en el programa Tot un Món el 18 de Noviembre de 2006

20 Focus groups celebrados el 22 y 29 de marzo de 2009 en la Facultad de Geografía e Historia de la UB con 6 mediadoras interculturales marroquíes de entre 25 y 35 años.

21 Ibid. 
A. García et. al Velos, burkas... moros: estereotipos y exclusión de la comunidad musulmana...

"Los programas españoles cuando presentan Marruecos, lo hacen por su lado menos desarrollado, las ciudades atrasadas, las mujeres atrasadas. Todo se muestra como atrasado y sucio”.

Las mujeres establecen juicios sobre el discurso emitido en los programas que visionan, criticando sus contenidos y ofreciendo alternativas de representación:22

“Estos programas son acertados pero a mi punto de vista muy mejorables.

Porque se tienen que dejar los estereotipos y dejar de decir "la mujer que lleva un pañuelo es una inculta”. No sabe muchas cosas, no es inteligente, no sabe conducir. Yo llevo coche desde hace muchos años y, como yo leo bien los labios, a veces en los semáforos veo gente diciendo "que hace esa mora con pañuelo conduciendo” ¿Qué hace esa mora con un coche”?

En este caso, una mujer explicita su experiencia personal como objeto del estereotipo de alteridad al hacer referencia a la reacción de gran parte de la población cuando la ve conducir su coche con el pañuelo puesto. Su actitud ambigua a medio camino entre la afirmación de la diferencia simbolizada por el hijab y la negación de esta misma distinción cultural al mostrarse activa en el espacio público, rompe los vínculos de asociación entre la religión islámica y la procedencia marroquí por una parte, con la sumisión femenina y la reclusión doméstica por la otra.

La preocupación de estas mujeres en las políticas de representación llevadas a cabo por los medios de comunicación hace que tiendan a ponerse en el sitio de los directores y productores televisivos: 23

"Yo cogería una familia normal, pondría la cámara pronto por la mañana para mostrar como la mujer se levanta para ir a trabajar., porque es la realidad de hoy en día sobre todo entre los inmigrantes, porque los hombres están muchos en el paro. Ver como el hombre se queda haciendo las tareas de la casa. Dejar de presentar el estereotipo de la familia donde la mujer va por detrás, de la mujer sometida y de la mujer que va con el pañuelo. Hay hombres que se levantan y llevan a los niños al cole y los van a recoger... y los llevan a la piscina, y les dan de comer ¿Por qué no enseñan una familia como ésta?”

Con esta contrapropuesta de representación inversa en la recepción el mensaje mediático, las mujeres arabo-musulmanas evidencian el carácter socialmente construido del estereotipo femenino oriental, al tiempo que reivindican implícitamente su propia agencia y subjetividad en las políticas públicas de representación, para así tomar un control mayor de su propia identidad social. En este sentido, se observa como las identidades alterizantes que se les adjudica, junto con las disciplinas de integración que se derivan, no concuerdan con su experiencia personal.

22 Ibid.

23 Ibid 
La negación de su diferencia por parte las barcelonesas procedentes de países musulmanes va acompañada muchas veces con la reivindicación del velo islámico como elemento distintivo de exteriorización de la propia identidad. Esto se observa cuando se propone la aparición en los medios de comunicación de chicas musulmanas con pañuelo asistiendo a sus clases en la universidad: 24

“También que enseñen que aunque llevan pañuelo salen y van a la universidad y tienen hijos bien educados “

Se busca de esta manera el contraste de representaciones y situaciones en principio antagónicas, en este caso la significación del hijab y la educación pública femenina, para así hacer evidente el estereotipo como un prejuicio y una convención social.

En esta situación de debate abierto la evidencia del estereotipo en los discursos institucionales y mediáticos es puesta encima de la mesa. Es precisamente en este momento cuando normalmente las mujeres, cuya identidad se ve agredida por representaciones de la alteridad que no controlan, toman la palabra y formulan sus reivindicaciones. En el caso de las mujeres marroquíes, se desea la normalidad la presencia del velo islámico en el ámbito público:25

“¿Habéis visto en España una mujer con velo cara al público?, en Francia sí [...] A nosotras no se nos acepta. Fuera del contexto relacionado con la mediación no hay ninguna mujer trabajando con pañuelo. Yo en las pocas entrevistas que he podido hacer para un puesto de administrativo me han dicho "¿sabes que el pañuelo te lo tienes que quitar?”

Lejos de demandar el reconocimiento del deber de la mujer de quedarse enclaustrada en casa al servicio del marido, las mujeres musulmanas reivindican el derecho a llevar el hijab en el espacio público, desligándolo de cualquier connotación de domesticidad y sumisión femenina ni de exhibición de un Islam mal interpretado y rechazado. Al mismo tiempo, se asume como normal que la mujer identificada con el Islam o el mundo árabe trabaje fuera de casa y gane independencia económica con respecto a su marido.

\section{CONCLUSIONES}

Como se ha podido observar en el presente artículo, en nuestras entrevistas colectivas, se confirman los estereotipos que recaen sobre la mujeres inmigrante musulmana oriental a través de los comentarios de los sujetos no alterizados, las mujeres autóctonas no musulmana.

\footnotetext{
24 Ibid.

25 Ibíd.
} 
A. García et. al Velos, burkas... moros: estereotipos y exclusión de la comunidad musulmana...

Por otro lado podemos observar como la recepción de las mujeres musulmanas quiebra el discurso orientalista de diferenciación cultural y sus connotaciones de género. Sin embargo aunque sí hace que el estereotipo sea evidente y explícito y lo denuncia, difícilmente ofrece alternativa clara. Es por ello que estas mujeres reivindican su propia agencia y subjetividad en las políticas públicas de representación.

No hay duda de que la identificación de procesos de producción y transmisión de representaciones que no encajan en la coherencia del discurso dominante, constituye una tarea imprescindible para desmontarlo y de esta manera desesencializar las culturas a las que enfrenta. Precisamente, el esencialismo cultural se ha convertido en uno de los principales obstáculos para el éxito de los principales planteamientos de integración de las minorías postcoloniales en los estados nación occidentales, tanto los basados en la idea de asimilación, como las propuestas multiculturalistas que ponen énfasis en la diferenciación (Nash,M. 2001)

Estos estereotipos excluyentes se han vehiculado en gran medida por el discurso institucional y recogidos y reelaborados por los medios de comunicación que contribuyen en gran medida a su difusión en amplios ámbitos de nuestra sociedad.

Una posibilidad de encontrar una solución a esta situación que obstaculiza la salida de los límites que imponemos a la comunidad musulmana, es darle voz para permitirle una autorepresentación que pueda contrarrestar los estereotipos de que son víctima.

Las aportaciones de las mujeres alterizadas y su experiencia, que hace que se cuestionen los estereotipos, permite ir más allá de binomios de representación orientalistas de raíz colonial. Es así que las ciencias sociales podrían, precisamente, contribuir a desmontar estos estereotipos por medio de estudios encaminados a sensibilizar la opinión pública y los responsables políticos. Al mismo tiempo podrían, en el marco de sus estudios, ofrecer a las musulmanas y musulmanes un espacio para su autorepresentación.

\section{BIBLIOGRAFÍA}

ABDELKADER, MOHAMENT ALÍ (2008): Monográfico sobre las mujeres. El Islam, n². AHMED, LEILA (1992): Women and Gender in Islam: Historical Roots of a Modern Debate. New Haven: Yale University Press.

AIXELÀ, YOLANDA (1 agosto de 2001): ¿Qué nos ofende de los “moros”? Discursos sobre los musulmanes y sus prácticas sociales. Scripta Nova. Revista Electrónica de Geografía y Ciencias Sociales, n94 (59), www.ub.edu/geocrit/sn-9459.htm

ARQUERO, HISHAM (1990): Acerca del Islam: “La mujer en el islam”, Córdoba: Universidad Islámica Internacional Averroes de Al-Andalus. www.geocities.com/ musulmanesnuevos/la mujerenislam.html 
BHABHA, HOMI ( 1994 ) (1 $1^{\text {a }}$ edición 1983): The Location of Culture. New York: Routledge

BADRAN, MARGOT (2009): Feminism in Islam: Secular and Religious Convergences. Oxford: Oneworld publications

BENHABIB, SHEILA (2002): The Claims of Culture.Diversity Equality and in the Global Era. Princeton, NJ: Princeton University Press.

- (2005) Los derechos de los otros. Barcelona: Gedisa.

BRACCO, MARÍA CAROLINA (2007): El Velo. Fantasía oriental, realidad occidental. Un aporte a la mirada Occidental Orientalista. Ponencia presentada en el I Congreso Internacional Oriente-Occidente: Los campos de la diversidad y el encuentro, Universidad de Buenos Aires, 2 de mayo de 2007. http://www.naya.org.ar/eventos/1cioo.htm

CASAS, MARTA (13 julio de 1998): Recensión de MANYER, Josep: Quan l’Islam truca a la porta. Per a una aproximació cultural als musulmans de Catalunya. Biblio $3 W$. Revista Bibliográfica de Geografía y Ciencias Sociales, ${ }^{\circ}$ 102, http://www.ub.edu/geocrit/b3w-102.htm

DELGADO, M ${ }^{a}$ CONCEPCIÖN (2009): Comunión y responsabilidad. En León. E. ed., Los rostros del Otro. Reconocimiento, invención y borramiento de la alteridad, 12-24 Rubí: Anthropos.

DÍAZ FREIRE, JAVIER (2003): Cuerpos en conflicto. La construcción de la identidad y la diferencia en el País Vasco a finales del siglo XIX. EN Nash, M.; Marre, D.eds., El desafío de la diferencia. Representaciones culturales e identidades de género, raza y clase, 61-94. Bilbao: Servicio Editorial de la Universidad del País Vasco.

ESTRUCH, JOAN (et al.) (2007): Las otras religiones: Minorías religiosas en Cataluña. Barcelona: Icaria

FORTI, ROMINA (2005): La identidad de la Mujer Musulmana. Observatorio de conflictos, http://www.nodo50.org/observatorio/mujer musulmana.htm

GONZÁLEZ, JOSÉ ANTONIO (1993): La extraña seducción. Variaciones sobre el imaginario exótico de Occidente. Granada: Universidad de Granada.

(2006): Lo moro: las lógicas de la derrota y la formación del estereotipo islámico?. Madrid: Anthropos.

HALL, Stuart (ed.) (1997): Representation. Cultural Representations and Signifying practices. London: Sage

KILANI, MODHER (1994): L'invention de l'autre. Essais sur le discours anthropologique. París: Editions Payot Laussanne.

LAMRABET, ASMA (2002): La eterna problemática de la mujer musulmana. Webislam www.webislam.com/articulos/26227-, Abril, 2, 2002.

- (2004): La mujer musulmana: entre la usurpación de derechos y los estereotipos. Webislam http://www.webislam.com/articulos/27328, Agosto, 30, 2004.

LÓPEZ, BERNABÉ (2000): El Islam y la Integración de la inmigración en España. Cuadernos de Trabajo Social, nº15, 129-143.

MANYER, JOSEP (1996): Quan L'Islam truca a la porta [1992]. Barcelona: Fundació Serveis de Cultura Popular-Altafulla.

MARTÍN, ELOY (2002): La imagen del magrebí en España: Una perspectiva histórica Ss. $X V I-X X$. Barcelona: Bellaterra

MARTÍN MUÑOZ, GEMA (2000): Imágenes e imaginarios. La representación de la mujer musulmana a través de los medios de comunicación en occidente. En 
A. García et. al Velos, burkas... moros: estereotipos y exclusión de la comunidad musulmana...

Valcárcel, A.; Renau, M.A.; Romero, R. eds., Los desafíos del feminismo en el siglo XXI, Sevilla: Instituto Andaluz de la Mujer.

MATEO, JOSEP LLUÍS (1997): El "moro" entre los primitivos. El caso del protectorado español en Marruecos. Barcelona: Fundació La Caixa.

MERNISSI, FATIMA (2001): El velo y el terror. Webislam http://www.webislam.com/articulos/18736-el_velo_y_el_terror.html, Febrero, 23, 2001.

MOHANTY, CHANDRA TALPADE Y RUSSO, ANN (1991): Third World women and the politics of feminism. Indiana: University Press.

MORERAS, JORDI (1999): Musulmanes en Barcelona. Espacios y dinámicas comunitarias. Barcelona: CIDOB edicions.

-(1 abril 2001): Pluralidad, reconocimiento y cotidianidad. La integración del islam en Europa. Revista Mugak, n015 http://revista.mugak.eu/articulos/show/136

MOUALHI, DJAOUIDA (2000): Mujeres musulmanas: estereotipos occidentales versus realidad social. Revista de Sociología, no 60, 291-304.

NASH, MARY (2001): Diversidad, multiculturalismos e identidades: perspectivas de género. En Marre, D. y Nash, M.eds., Multiculturalismo y género. Un estudio multidisciplinar, 21-47. Barcelona: Bellaterra.

- (2002): Los nuevos sujetos históricos: perspectivas de fin de siglo. Género, identidades y nuevos sujetos históricos. En Romeo, M.C y Saz, I.eds., El siglo XX: historiografía e historia85-100. Valencia: Universitat de Valencia.

- (2004): Mujeres en el mundo. Historia, restos y movimientos. Madrid: Alianza.

- (2005): Inmigrantes en nuestro espejo. Inmigración y discurso periodístico en la prensa española. Barcelona: Icaria.

NASH, MARY Y VIVES, ANTONI (2008): La construcción del inmigrante: prácticas discursivas político-institucionales. En Tello,R.; Benach,N; Nash,M. eds., Intersticios. Contactos interculturales, género y dinámicas identitarias en Barcelona, 29-89 Barcelona: Edicions Bellaterra.

NASH, MARY; VIVES, ANTONI; TORRES, GEMMA (2012) De Warner Bros a You Tube pasando por Barcelona: sexo, machismo e inmigración en Borat. En Cantero, M. ed., Migración y cine en el contexto español,(en prensa). València: Tirant lo Blanch.

ROBINSON, FRANCIS (1990): El mundo islámico. Barcelona: Folio.

SABIDO, OLGA (2009): Sorpresa y repugnancia. En León, E. ed., Los rostros del Otro. Reconocimiento, invención y borramiento de la alteridad, 25-57. Barcelona: Anthropos.

SAID, EDWARD W. (1978): Orientalism. New York: Vintage.

SANTAMARÍA, ENRIQUE (2002): Inmigración y barbarie. La construcción social y política del inmigrante como amenaza. Papers. Revista de sociologia, $\mathrm{n}^{\circ} 66,59-75$.

SPIVAK, GAYATRI (1994): Can the Subaltern Speak. En Williams,P. y Chrishan,L. eds., Colonial Discourse and Postcolonial Theory. A reader, 66-111 Nova York: Harvester/Whearsheaf. 